\title{
Comparing the Fatty Acid Composition of Organic and Conventional Milk
}

\author{
K. A. Ellis, ${ }^{* 1}$ G. Innocent, ${ }^{\star}$ D. Grove-White, $\dagger$ P. Cripps, $\dagger$ W. G. McLean, $\neq$ \\ C. V. Howard, $\S$ and M. Mihm\# \\ *Division of Animal Production and Public Health, University of Glasgow Veterinary School, Bearsden Road, Bearsden, \\ Glasgow, G61 1QH, UK \\ †Division of Livestock Health and Welfare, University of Liverpool, Faculty of Veterinary Medicine, Leahurst, \\ Neston, CH64 7TE, UK \\ ‡Department of Pharmacology \& Therapeutics School of Biomedical Sciences, Sherrington Buildings, Ashton Street, \\ Liverpool, Merseyside, L69 3GE, UK \\ $\S$ Centre for Molecular Biosciences, University of Ulster, Cromore Road, Coleraine, Co. Londonderry, BT52 1SA, UK \\ \#Division of Cell Sciences, Institute of Comparative Medicine, University of Glasgow Veterinary School, Bearsden Road, \\ Bearsden, Glasgow, G61 1QH, UK
}

\begin{abstract}
During a 12-mo longitudinal study, bulk-tank milk was collected each month from organic $(\mathrm{n}=17)$ and conventional $(\mathrm{n}=19)$ dairy farms in the United Kingdom. All milk samples were analyzed for fatty acid (FA) content, with the farming system type, herd production level, and nutritional factors affecting the FA composition investigated by use of mixed model analyses. Models were constructed for saturated fatty acids, the ratio of polyunsaturated fatty acids (PUFA) to monounsaturated fatty acids, total n-3 FA, total n-6 FA, conjugated linoleic acid, and vaccenic acid. The ratio of n-6:n-3 FA in both organic and conventional milk was also compared. Organic milk had a higher proportion of PUFA to monounsaturated fatty acids and of n-3 FA than conventional milk, and contained a consistently lower n-6:n-3 FA ratio (which is considered beneficial) compared with conventional milk. There was no difference between organic and conventional milk with respect to the proportion of conjugated linoleic acid or vaccenic acid. A number of factors other than farming system were identified which affected milk FA content including month of year, herd average milk yield, breed type, use of a total mixed ration, and access to fresh grazing. Thus, organic dairy farms in the United Kingdom produce milk with a higher PUFA content, particularly n-3 FA, throughout the year. However, knowledge of the effects of season, access to fresh grazing, or use of specific silage types could be used by producers to enhance the content of beneficial FA in milk.
\end{abstract}

Received September 23, 2005.

Accepted December 20, 2005.

${ }^{1}$ Corresponding author: k.ellis@vet.gla.ac.uk
Key words: organic farming, fatty acid, n-3 fatty acid, conjugated linoleic acid

\section{INTRODUCTION}

Bovine milk contains a large number of fatty acids (FA), some of which may be of potential benefit to human health, including polyunsaturated fatty acids (PUFA) in the n-3 (omega-3) FA group and the conjugated linoleic acid (CLA) isomer cis-9 trans-11 C18:2 (Jensen, 2002). The principal n-3 FA in milk is $\alpha$ linolenic acid (C18:3), along with smaller amounts of docosahexaenoic acid (C20:5) and eicosapentaenoic acid (C22:6). The n-3 FA have been linked to improved neurological function (Contreras and Rapoport, 2002), protection against coronary heart disease (Bucher et al., 2002; Hu and Willett, 2002), and prevention of some forms of cancer (Rose and Connolly, 1999; Saadatian-Elahi et al., 2004). It is recommended, therefore, that consumers increase their intake of n-3 FA, with an optimum ratio of $1: 1$ between $n-6$ and $n-3$ FA in the human diet, rather than the $>10: 1$ ratio found in some Western diets (Simopoulos, 2002). Additionally, increasing the overall total PUFA content of the diet is considered beneficial to human health with respect to reducing cardiovascular disease ( $\mathrm{Hu}$ and Willett, 2002). Conjugated linoleic acid has been shown to protect against cancers in vitro (Ip et al., 1991), and has been associated with antiatherogenic and antiobesity functions (Whigham et al., 2000). The FA profile of bovine milk depends both on the consumed FA and on biohydrogenation processes occurring in the rumen. Thus, many factors affect the FA composition of bovine milk, including breed (White et al., 2001), season (Lock and Garnsworthy, 2003), geographical location (Thorsdottir et al., 2004a), access to fresh grazing (Hebeisen et al., 1993; Kelly et al., 1998), grazing sward type (Hauswirth et al., 2004), silage type (Dewhurst et al., 
2003), cereal feeding (Wijesundera et al., 2003), and oil supplementation of feed (Grummer, 1991; Palmquist et al., 1993; Offer et al., 2001). Recent work has shown significant increases in the $\alpha$-linolenic acid (C18:3) proportion in the milk FA profile of cows fed clover silage (Dewhurst et al., 2003). Milk certified to be organic under European Union standards might have a favorable FA profile with respect to n-3 FA, because many organic dairy farms utilize clover as a forage crop, both for grazing and ensiling. However, no large-scale longitudinal studies have investigated the effects of differences in management systems between organic and conventional farms within the United Kingdom on the FA profile of the milk produced. Several studies have investigated the effects of organic farming systems on the CLA content of milk, but results differ, with some authors reporting a higher CLA content in organic milk (Jahreis et al., 1996; Bergamo et al., 2003), whereas others reported no difference (Toledo et al., 2002). These studies have also tended to be small-scale and involved farms not representative of UK dairy systems. In the context of recent work to alter the composition of milk to provide a better source of PUFA and reduce the saturated FA (SFA) component (Chilliard et al., 2001; Voigt and Hagemeister, 2001), it is essential to determine seasonal, herd-level management, and nutritional factors that affect milk FA composition, which will allow the formulation of recommendations for producers aiming to enhance the content of beneficial FA in milk.

The aims of this study were to 1) determine whether there is a difference in FA composition of bulk-tank milk between organic and conventional farms in the United Kingdom; 2) investigate which herd and nutritional factors affect FA composition on organic and conventional farms in the United Kingdom; 3) investigate the seasonal effects on milk FA composition in the temperate UK climate on organic and conventional farms in the United Kingdom.

\section{MATERIALS AND METHODS}

\section{Milk Sample Collection}

Nineteen conventional and 17 organic dairy farms located in northwest England and in Wales were recruited for the 12-mo longitudinal study. All farms were visited monthly from May 2003 to April 2004. At each farm visit, a bulk-tank milk sample was collected and farm production data were obtained by interview questionnaire and farm record analysis. Data included the previous month's milk production quality and the current herd management and feeding practices and were entered into a database (Microsoft Access, 2000, Microsoft Corp., Redmond, WA). Individual farm bulk- tank milk samples were collected into sterile $30-\mathrm{mL}$ plastic screw-top containers after stirring the bulk tank for at least 2 min. All samples were frozen at $-80^{\circ} \mathrm{C}$ until analysis. One organic farm dried off the whole herd for $2 \mathrm{mo}$; therefore, data were included for only 10 mo for that farm.

\section{Sample Analysis}

A total of 430 milk samples were transported on ice to the Institute of Grassland and Environmental Research Laboratory (Aberystwyth, Wales, UK) for analysis of FA content. This is a commercial laboratory where FA methyl esters were prepared and analyzed by gas chromatography using the method of Sukhija and Palmquist (1988). Results were transformed to present each individual FA as a percentage of the total FA in the milk fat sample.

\section{Statistical Analyses}

Factors Affecting the Proportions of FA in Milk. Data were analyzed using Excel (Microsoft) and Minitab (Minitab Inc., 2003, State College, PA) software. Milk FA data were grouped into SFA, monounsaturated (MUFA), PUFA, total n-3, and total n-6 FA. Total n-3 FA comprised the sum of C18:3 ( $\alpha$-linolenic), C20:3, $\mathrm{C} 20: 5$ (eicosapentaenoic acid), C22:5, and C22:6 (docosahexaenoic acid). Total n-6 FA comprised C18:2 (linoleic acid), C18:3-gamma, C20:3, and C20:4 (arachidonic acid). In addition, 2 important products of biohydrogenation of C18:2 and C18:3, the main CLA isomer C18:2 cis-9 trans-11, and vaccenic acid (C18:1 trans11), were investigated. The overall mean and standard deviation (SD) proportion of each FA group type, CLA, and vaccenic acid were calculated as a percentage of the total FA content for both organic and conventional milk over the whole year.

To initially investigate farm system differences on milk FA proportions, the effect of farm system type (organic or conventional) was compared using a general linear mixed model (GLMM) approach including individual farm identity and month of sampling, where farm identity was nested within farming system type. Secondly, to enable other potentially confounding farm management and nutritional factors to be accounted for, the GLMM approach was revised and repeated to include additional factors as well as farm type, farm identity, and month. The following additional factors were investigated: cow breed, herd average annual yield, herd calving pattern, and monthly herd-level nutrition factors. Each factor was divided into factor levels and coded; with breed level according to the proportions of different breed types in the herd, herd 
Table 1. Details of how factor levels were constructed for the major herd-level factors: cow breed, herd average annual yield, and herd calving pattern (farms could have a different level for each factor)

\begin{tabular}{llll}
\hline & \multicolumn{3}{c}{ Factor type (no. of farms in each level) } \\
\cline { 2 - 4 } $\begin{array}{l}\text { Factor } \\
\text { level }\end{array}$ & Breed type & $\begin{array}{l}\text { Herd average } \\
\text { yield quartiles } \\
\text { (L/cow per year) }\end{array}$ & Calving pattern \\
\hline 1 & $>95 \%$ herd are Holstein-Friesian type cows (17) & $<6,025(9)$ & $\begin{array}{l}\text { Year-round calving (26) } \\
\text { Seasonal calving (7) }\end{array}$ \\
2 & $>95 \%$ herd are pedigree Holstein (11) & $6,025-7,199(8)$ & Block calving throughout year (3) \\
3 & $>95 \%$ herd are pedigree Friesian (3) & $7,200-7,974(10)$ & - \\
\hline
\end{tabular}

average annual yield level based on the quartile ranges of herd yield, and calving pattern based on whether there was a distinct calving pattern or year round calving (Table 1). Thus, a farm could have a different level for each factor. Similarly, farm-level cow nutrition data collected at each monthly farm visit during the sampling year were assigned either binary or multilevel coding as appropriate (Table 2).

Individual herd-level and nutritional factors were first screened using a GLMM that also included farm identity as a random effect and month as a fixed effect to determine their significance on the proportions of the FA. All herd-level and nutritional factors significant at screening $(P<0.2)$ were carried forward to a final multivariable model. This model consisted of

$$
\begin{gathered}
\text { FA proportion }_{i j k l}=\mu+F_{i} \mid H L F_{j} \\
+H F_{j}+N_{k}+M_{l}+\varepsilon_{i j k l}
\end{gathered}
$$

where $\mu=$ the overall mean FA group proportion, $F_{i}=$ the individual farm effect which was nested within $\mathrm{HLF}_{\mathrm{j}}$ the herd level factor, $\mathrm{N}_{\mathrm{k}}=$ the nutrition variable, $\mathbf{M}_{1}=$ the month effect, and $\varepsilon_{\mathrm{ijkl}}=$ the residual error term. Month was included as a fixed effect because it was intended to determine whether there were effects of specific months of the year on milk FA content. The data structure was hierarchical, with individual farms nested within the herd-level factors; for example, farms within farm type. All herd-level factors were included as fixed effects. Multivariable models were

Table 2. Coding assigned to all nutritional factors screened for significance, where factor levels are recorded for each farm at each month

\begin{tabular}{|c|c|c|}
\hline Factor & Level & Description of level \\
\hline High or low concentrate feed in parlor & Low & Amount fed is $<$ median level fed \\
\hline & 1 & Yes \\
\hline \multirow[t]{2}{*}{ Whole-crop fed } & 0 & No \\
\hline & 1 & Yes (any type of whole crop) \\
\hline \multirow[t]{2}{*}{ Corn silage fed } & 0 & No \\
\hline & 1 & Yes \\
\hline \multirow[t]{2}{*}{ Hay fed } & 0 & No \\
\hline & 1 & Yes \\
\hline \multirow[t]{2}{*}{ Any other conserved forage fed } & 0 & No \\
\hline & 1 & Yes \\
\hline Grazing type & 0 & No grazing \\
\hline & 1 & Feeding grass silage \\
\hline & 2 & Feeding red clover silage \\
\hline & 3 & Feeding white clover silage \\
\hline & 4 & Feeding mixed clover silages \\
\hline
\end{tabular}
of sampling

\footnotetext{
${ }^{1}$ TMR fed through a mixer.
} 
developed using a backwards elimination approach, with factors removed depending on the significance of the $F$-test for that factor. All possible, biologically plausible 2-way interaction terms were then tested for significance. For main effects and for interaction terms, significance was determined as $P<0.05$ for the corresponding $F$-test.

For factors remaining in the model, posthoc multiple comparisons of means for each factor level were calculated using a pairwise comparison method and the Bonferroni correction for multiple comparisons, where significance was defined as $P<0.05$. To maintain the hierarchy of the variables if farm type (i.e., organic or conventional) and another herd level factor (i.e., yield) remained significant in the model, the 2 major factors were combined to create one factor. For example 'organic' + 'yield levels 1 to 4' or 'conventional' + 'yield levels 1 to 4'. This means that farm type can be compared at the same yield level; for example, low-yielding organic (organic + yield level 1) and low-yielding conventional farms (conventional + yield level 1). Results of the final multivariable analyses for the following FA groups are presented: SFA, PUFA:MUFA, n-3 FA, n-6 FA, vaccenic acid, and CLA.

Ratio of n-6 to n-3 FA in Organic and Conventional Milk. The ratios of percentages of these 2 groups of FA in individual monthly organic and conventional milk samples were calculated. A GLMM approach similar to that described previously was used to determine the effects of farm type (conventional or organic) and month, with individual farm identity as a random factor nested within farm type. Significance was ascribed to a factor if the $P$-value of the $F$-test was $<0.05$. Posthoc factor level comparisons for the effect of month were calculated using a pairwise comparison method and the Bonferroni correction for multiple comparisons.

\section{RESULTS}

\section{Mean Percentage of FA Groups in Organic and Conventional Milk over 12 Mo}

The mean percentage of each of the FA groups in both organic and conventional milk averaged over the 12 mo of the study is shown in Table 3. Conventional and organic milk did not differ with respect to milk SFA content, but conventional milk had a higher percentage of MUFA compared with organic milk $(P<$ 0.01 ) and, conversely, organic milk had a higher percentage of PUFA compared with conventional milk ( $P$ $<0.01$ ). The mean n-3 FA content in organic milk was approximately 1.7 times higher than in conventional milk $(P<0.01)$. There was no difference in the mean percentages of n-6 FA, vaccenic acid, or CLA in organic and conventional milk.

\section{Factors Affecting the Proportions of Milk FA Groups}

All coefficients for significant factors for each of the multivariable models for the FA groups are summarized in Tables 4, 5, and 6. A positive coefficient indicates an effect to increase the FA proportion and a negative coefficient indicates a decrease in FA proportion.

SFA. There were highly significant effects (Table 4; $P<0.001$ ) of both individual farm and month on the proportion of SFA in milk FA, wherein SFA proportions were higher $(P<0.05)$ in the fall and winter months (October-December) compared with the spring and early summer (March-June; Figure 1a). The use of a TMR increased the proportion of milk SFA overall $(P<0.001)$, even during spring and summer (interaction $P<0.05$ ). Feeding of both corn silage and whole crop increased milk SFA proportions $(P<0.05)$. Increased SFA proportions were also seen when white clover silage, red-clover silage, or grass silage were fed compared with no silage feeding $(P<0.01, P<0.01$, and $P<0.05$ respectively). However, grazing of both grass and white clover swards were associated with a significantly lower milk fat SFA proportion compared with no grazing $(P<0.01)$.

\section{Ratio of PUFA:MUFA}

There were highly significant effects (Table $4 ; P<$ 0.001) of both individual farm and month on the ratio of proportions of PUFA to MUFA in milk FA. The ratio of PUFA to MUFA was higher in organic milk compared with conventional milk for the whole $12 \mathrm{mo}$ $(P<0.001$; Figure 1b). In addition, a farming system $\times$ month interaction was observed $(P<0.05)$ in which the PUFA:MUFA ratio in conventional milk decreased between September and March $(P<0.001)$. Feeding red clover silage was associated with an increased PUFA to MUFA ratio compared with feeding grass silage $(P<0.01)$ and white clover silage $(P<0.001)$. However, when a high level of concentrate feeding inparlor was used, the ratio of PUFA to MUFA decreased $(P<0.001)$; this effect was also observed in association with red-clover silage feeding $(P<0.001)$.

$\boldsymbol{n - 3} \boldsymbol{F A}$. At the initial screening analysis, the proportion of total n-3 FA was affected by farm type, yield, and breed. Therefore, 2 models were constructed because it was not possible to combine all major herdlevel effects into a single model using the nested design approach (model 1 = farm type and breed; model $2=$ 
Table 3. Mean (SD) percentage of each group type of fatty acid (FA; \% of total FA) averaged over the 12 mo of sampling of each milk type

\begin{tabular}{llc}
\hline & \multicolumn{2}{c}{ Milk type } \\
\cline { 2 - 3 } FA group type & Conventional & Organic \\
\hline Saturated FA & $67.25(3.54)$ & $68.13(3.51)$ \\
Monounsaturated FA & $27.63(2.94)^{\mathrm{a}}$ & $26.19(3.01)^{\mathrm{b}}$ \\
Polyunsaturated FA & $3.33(0.66)^{\mathrm{a}}$ & $3.89(0.61)^{\mathrm{b}}$ \\
Total n-3 FA & $0.66(0.22)^{\mathrm{a}}$ & $1.11(0.25)^{\mathrm{b}}$ \\
Total n-6 FA & $1.68(0.46)$ & $1.68(0.44)$ \\
C18:1 trans-11 (vaccenic) & $1.75(1.09)$ & $2.06(0.96)$ \\
C18:2 cis-9, trans-11 (conjugated linoleic acid) & $0.58(0.34)$ & $0.65(0.28)$ \\
\hline
\end{tabular}

\footnotetext{
${ }^{\mathrm{a}, \mathrm{b}}$ Different superscripts indicate highly significant differences $(P<0.01)$ in FA group type between organic and conventional milk samples.
}

farm type and yield). In both models, there were highly significant effects (Table $5 ; P<0.001$ ) of individual farm and month on the proportion of n-3 FA in milk FA, in which proportions of n-3 FA increased in April and August. Figure 1c shows the mean n-3 FA content in each milk type over the 12-mo period. In the farm type and breed type model (model 1), organic farms had a higher milk n-3 FA proportion compared with conventional farms of the same breed types $(P<0.01$ for all comparisons; Figure 2). In both organic and conventional farms, mixed breed herds (level 4) had significantly higher milk n-3 FA proportions compared with other breed types $(P<0.01)$. Grazing of grass was associated with a higher proportion of milk n-3 FA compared with no fresh grazing or mixed clover grazing $(P<0.01$ and $P<0.05$, respectively). In contrast, use of a TMR or feeding high levels of concentrate inparlor were associated with decreased milk n-3 FA ( $P$ $<0.01)$. An interaction between the use of a TMR and the concentrate feed level was significant, wherein TMR use together with low levels of in-parlor feed was associated with a decrease in milk n-3 FA proportion $(P<0.001)$. Additionally, an interaction between the type of silage fed and the concentrate feed level inparlor was significant $(P<0.01)$, with combined feeding of red-clover silage and high concentrate feed inparlor associated with a decrease in milk n-3 fatty acid proportions $(P<0.05)$. With these interaction terms included, the overall effect of silage type as a main effect was not significant.

In the farm type and yield level model (model 2), organic farms had higher milk n-3 FA proportions compared with conventional farms of the same yield levels $(P<0.01$ for all comparisons, Figure 3$)$. In conventional herds, the lowest yield level (level 1) had higher milk n-3 FA proportions compared with the highest yield level (level $4 ; P<0.01$ ). Apart from farm type and yield level, all factors and interactions were the same in this model as for the farm type and breed type model. n-6 FA. There were highly significant effects (Table $6 ; P<0.001$ ) of both individual farm and month on the proportion of n-6 FA in milk FA (Figure 1d). Milk n6 FA proportions were higher in March compared with September-December $(P<0.05)$. A significant interaction was seen between corn silage feeding and pit silage type $(P<0.01)$, where increased n-6 FA proportions were observed when corn silage was fed in conjunction with grass silage $(P<0.05)$.

Ratio of n-6 to n-3 FA. The mean monthly ratios of total n-6 and n-3 FA in organic and conventional milk samples are shown in Figure 1e. Organic milk has a highly significant, consistently lower ratio of $\mathrm{n}$ 6:n-3 FA throughout the year $(P<0.001)$ compared with conventional milk. All milk n-6:n-3 ratios were lower in the spring and summer (April-September) compared with the other months of the year $(P<0.01)$. The n-6:n-3 FA ratio each month in organic milk ranged from 1.27 to 1.90 , and in conventional milk, ranged from 1.99 to 3.66 . In organic milk the ratio was lowest in August and in conventional milk, the ratio was lowest in May.

Vaccenic Acid (C18:1 trans-11). There were highly significant effects (Table $6 ; P<0.001$ ) of both individual farm and month on the proportion of vaccenic acid in milk FA (Figure 1f). An increase in vaccenic acid proportion was recorded in spring and early summer (April and May) and a second, lower peak occurred in late summer (August; Figure 1f). Compared with fall and throughout winter (SeptemberMarch), the increase seen in April and May was highly significant $(P<0.01)$. The late summer peak in August dropped in September $(P<0.05)$. There was no effect of farm system type on the milk vaccenic acid proportion. Use of a TMR was associated with a decreased vaccenic acid proportion $(P=0.01)$. The effect of including silage type was significant overall $(P<0.01)$, with a difference seen between no silage feeding and grass silage feeding, in which milk vaccenic acid proportion increased 
Table 4. Significant factors affecting milk fatty acid (FA) proportions: Saturated FA and ratio of polyunsaturated to monounsaturated FA (PUFA:MUFA)

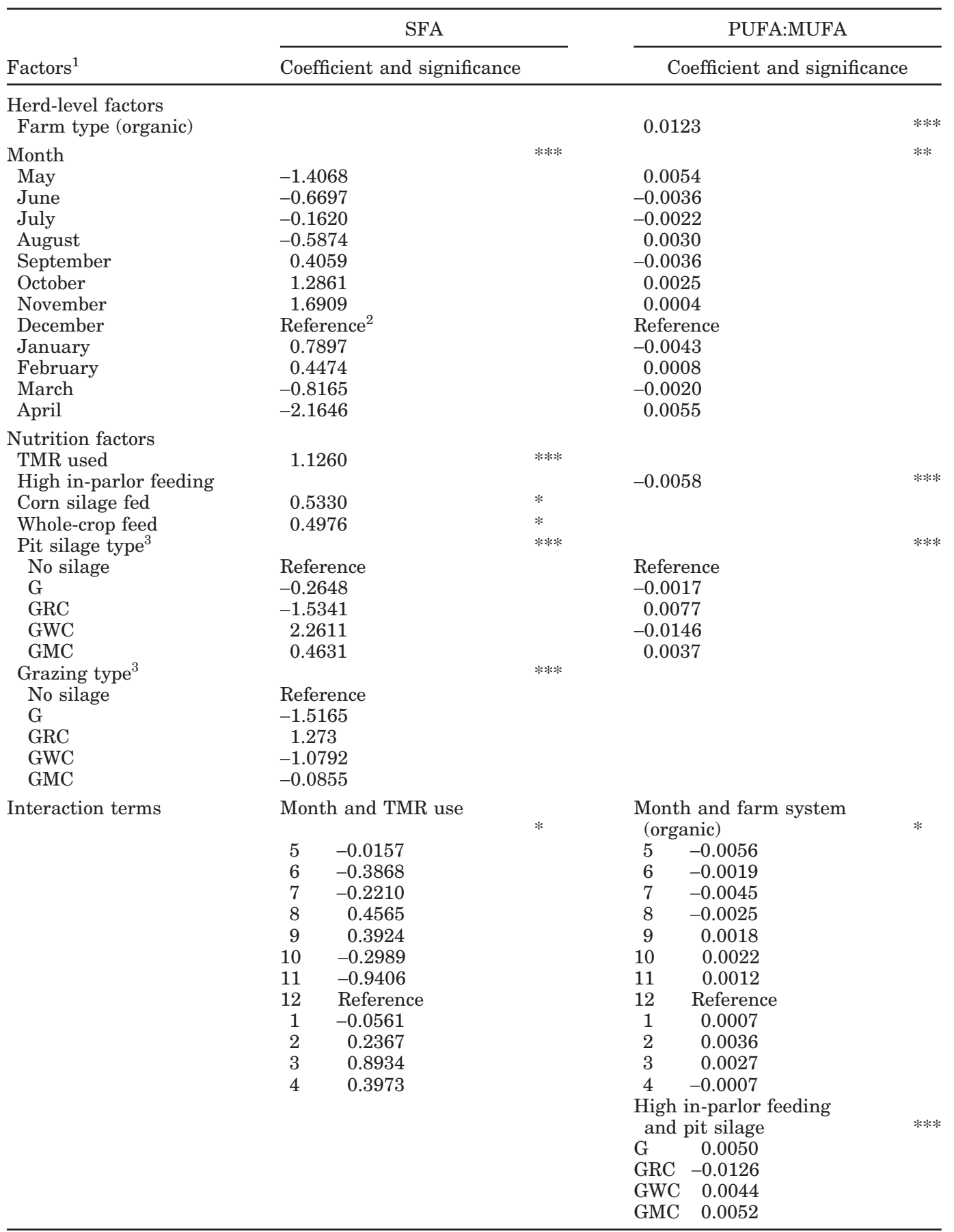

${ }^{1}$ Farm identity was highly significant in all models (individual farm coefficients not listed).

${ }^{2}$ Reference $=$ reference level for factor.

${ }^{3} \mathrm{G}=$ Grass; GRC = grass and red clover; $\mathrm{GWC}=$ grass and white clover; GMC $=$ grass and mixed clover. $* P<0.05 ; * * P<0.01 ; * * * P<0.001$.

in association with no silage feeding (animals were grazing only; $P<0.01)$. Grazing was a significant effect overall $(P<0.01)$, where grazing grass or white clover was associated with increased vaccenic acid proportions compared with no grazing $(P<0.05)$. An interaction between TMR use and pit silage type was signifi- 
Table 5. Significant factors affecting milk fatty acid (FA) proportions: n-3 FA model 1 (farm type and breed) and model 2 (farm type and yield)

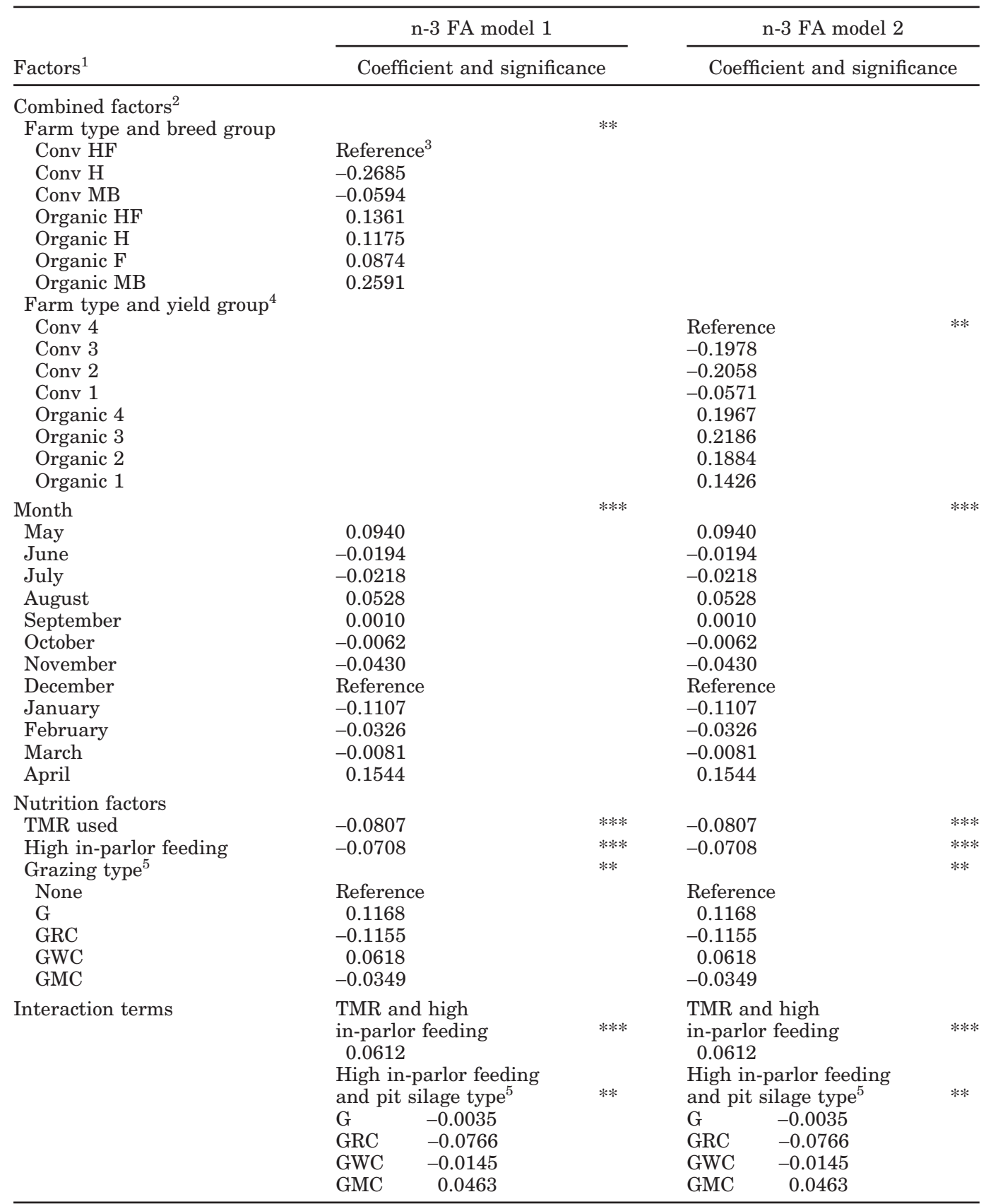

${ }^{1}$ Farm identity was highly significant in all models (individual farm coefficients not listed).

${ }^{2}$ For combined factors, significance value given for comparison of farm system type at the same level of the other part of the combined factor. Conv = conventional; $\mathrm{HF}=$ Holstein-Friesian; $\mathrm{H}=\mathrm{Holstein} ; \mathrm{F}=$ Friesian; $\mathrm{MB}=$ mixed breed.

${ }^{3}$ Reference $=$ reference level for factor.

${ }^{4}$ Yield quartile levels: 1 = lowest to 4 = highest.

${ }^{5} \mathrm{G}=$ Grass; GRC = grass and red clover; GWC = grass and white clover; GMC = grass and mixed clover. $* P<0.05 ; * * P<0.01 ; * * * P<0.001$. 
Table 6. Significant factors affecting milk fatty acid (FA) proportions: n-6 FA, vaccenic acid, and conjugated linoleic acid

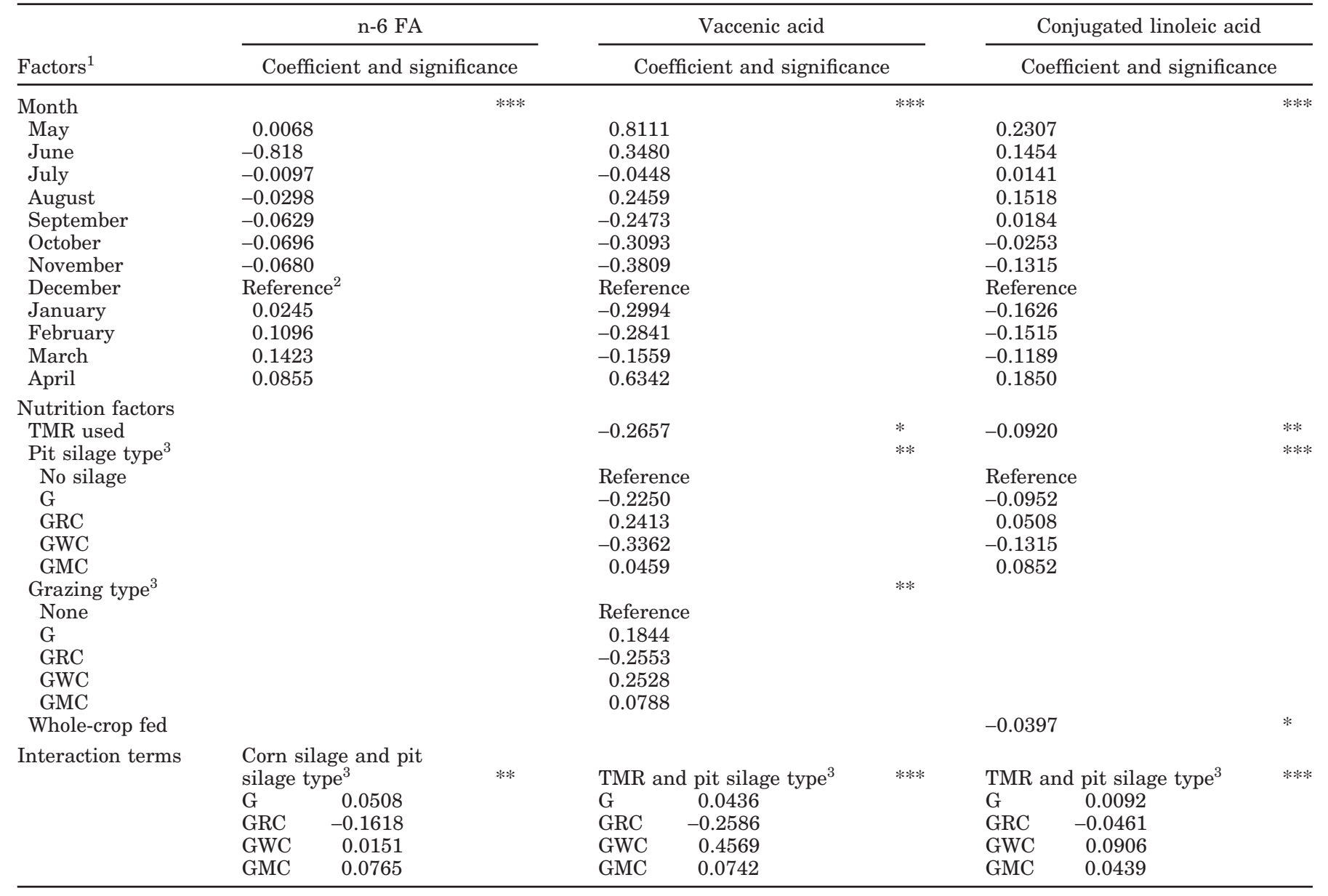

${ }^{1}$ Farm identity was highly significant in all models (individual farm coefficients not listed.)

${ }^{2}$ Reference $=$ reference level for factor.

${ }^{3} \mathrm{G}=$ Grass; GRC = grass and red clover; GWC = grass and white clover; GMC = grass and mixed clover.

$* P<0.05 ; * * P<0.01 ; * * * P<0.001$.

cant $(P<0.01)$. Use of a TMR was associated with lower, more consistent proportions of vaccenic acid, especially when used in conjunction with access to fresh pasture $(P<0.01)$.

$\boldsymbol{C L A}$. There were highly significant effects (Table 6; $P<0.001$ ) of both individual farm and month on the proportion of CLA in milk FA (Figure 1g). A seasonal effect was seen with increased CLA proportion in the early and late summer (April, May, June, and August). The peak CLA proportions in April and August were significantly higher than proportions found in January-March and October-December $(P<0.01)$. There was no effect of farm system type on the milk CLA proportion. Use of a TMR and feeding whole crop was associated with a decrease in milk CLA proportion ( $P$ $<0.05$ for both factors). Feeding of both grass silage and white-clover silage was associated with lower milk CLA proportions $(P<0.01$ and $<0.05$, respectively) compared with no silage feeding (animals were grazing only). An interaction with the use of a TMR and forage type was observed $(P<0.001$ for overall effect), where TMR use in association with no conserved silage feeding (i.e., grazing only) was associated with a lower milk proportion of CLA.

\section{DISCUSSION}

A number of factors were shown to affect the fatty acid content in milk. Firstly, organic milk had a higher proportion of PUFA and n-3 FA, and this effect of farming system remained significant even after accounting for some potentially confounding management and nutritional factors in the analyses. Secondly, a highly significant effect of month on the proportions of FA groups in both organic and conventional milk was observed in the multivariable models. Thirdly, a 

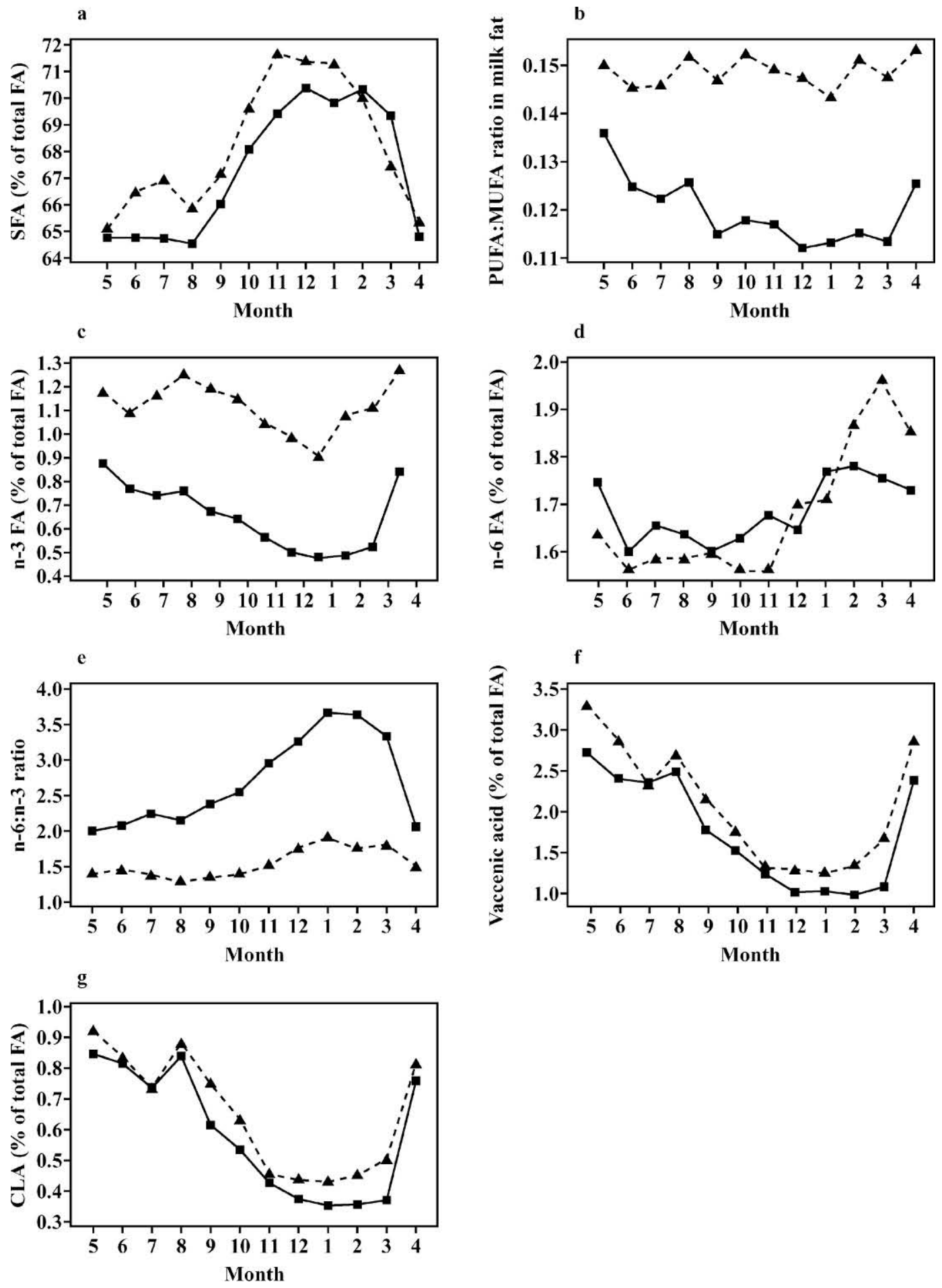

Figure 1. a) Percentages of saturated fatty acids (SFA); b) ratio of polyunsaturated FA (PUFA) to monounsaturated FA (MUFA); c) percentages of n-3 FA; d) percentages of n-6 FA; e) ratio of n-6:n-3 FA; f) percentage of vaccenic acid; and g) percentage of conjugated linoleic acid (CLA) in organic (A) and conventional ( $)$ milk each month for the 12-mo study (where month $5=$ May 2003 and month $4=$ April 2004). Mean values are taken across all farms of each type. 


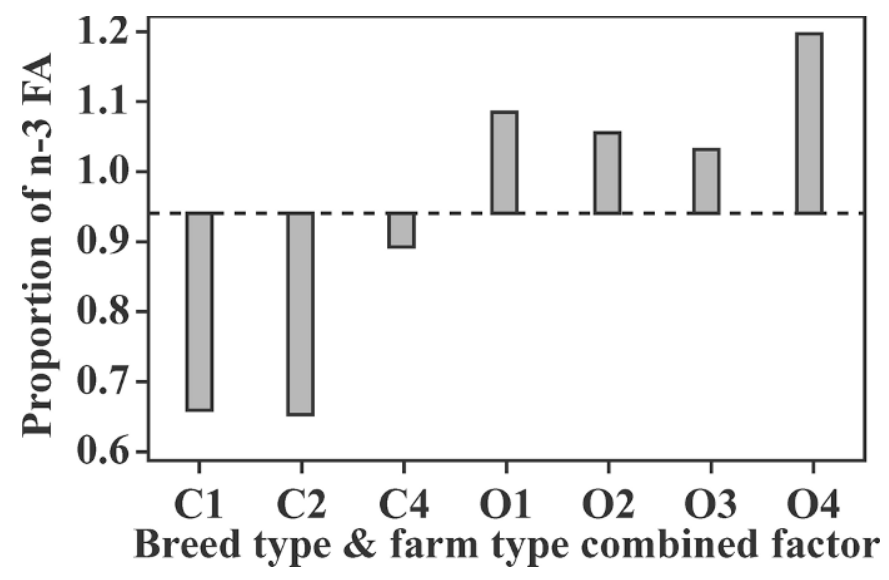

Figure 2. Effects of breed type and farm system type from model 1 on mean milk n-3 fatty acid (FA) proportion; $\mathrm{C} 1$ = conventional pedigree Holstein, $\mathrm{C} 2$ = conventional Holstein-Friesian, $\mathrm{C} 4$ = conventional mixed breed, $\mathrm{O} 1=$ organic pedigree Holstein, $\mathrm{O} 2=$ organic Holstein-Friesian, O3 = organic Friesian, and O4 = organic mixed breed (there were no conventional Friesian farms). Dashed line represents mean overall proportion of n-3 FA in all milk samples.

number of specific nutritional factors, such as TMR use, in-parlor concentrate feeding level, or silage type were seen to affect milk FA composition. Finally, individual farm variation affected the milk FA composition confirming large variability between individual farms.

Organic milk contained a higher proportion of PUFA and n-3 FA compared with conventional milk, whereas conventional milk had a higher proportion of MUFA, with these differences maintained over the duration of the study. This is the first study to consider a crosssection of UK farms over a 12-mo production cycle,

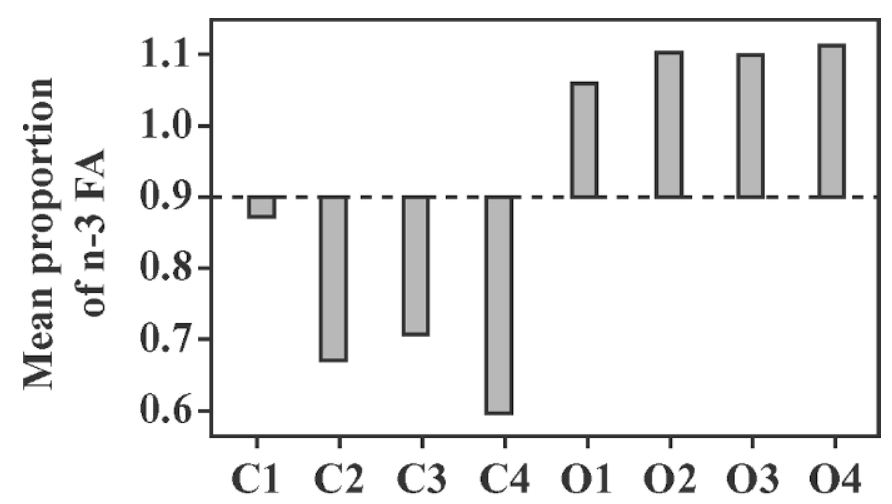

Farm system type/herd yield
level combined factor

Figure 3. Effects of herd-yield quartile and farm system type from model 2 on mean milk $n-3$ fatty acid (FA) proportion ( $\mathrm{C}=$ conventional, $\mathrm{O}=$ organic, 1 to $4=$ lowest to highest herd average yield quartile). Dashed line represents mean overall proportion of n-3 FA in all milk samples. and supports the hypothesis that organic milk has a higher n-3 FA content compared with conventional milk. Previous studies showed that experimental cows fed red and white clover silages produced milk with increased $\alpha$-linolenic (C18:3) content compared with cows fed grass silage (Dewhurst et al., 2003). Organic farms utilize clover more extensively than conventional farms as a forage crop, which may, in part, explain the main finding from the current study, of increased n-3 FA content in organic milk. However, the farm system differences remained, despite accounting for a number of nutritional and farm-level management effects; this suggests there are, as yet unaccounted farming system factors affecting milk FA composition. More detailed investigation of concentrate composition or subtler sward-type variation than that accounted for in these analyses are factors that will need to be investigated further.

The n-6:n-3 FA ratio was lower in organic milk compared with conventional milk, being closer to the suggested optimum n-6:n-3 FA ratio in the human diet of 1:1 (Simopoulos, 2002). Conventional milk from Iceland has been reported to have a higher n-3 FA content and a lower mean n-6:n-3 ratio (2.10:1) compared with milk from 4 other Nordic countries, where the ratio averaged 4.70:1 (Thorsdottir et al., 2004b). In the same study, a positive association between increasing milk n-6:n-3 FA ratio and the prevalence of type-2 diabetes and mortality due to coronary heart disease was found. Milk enriched with n-3 FA favorably alters the plasma fat content of volunteers, reducing the concentration of fats associated with increased risk of cardiovascular disease (Visioli et al., 2000; Baró et al., 2003; Carrero et al., 2004). Organic milk samples in this study had n-6:n-3 ratios even lower than those reported from Iceland (Thorsdottir et al., 2004b). There is now a strong need to verify a benefit to human health following consumption of low $n-6: n-3$ ratio (organic) milk.

In all samples, SFA decreased over summer, whereas PUFA and n-3 fatty acids increased in summer. The month effects most likely reflect changes in the composition of the grazed swards. Clearly, this is likely to occur gradually over time, rather than sudden changes from month to month. However, milk samples were only collected once per month and these samples are seen as fixed points of interest representing an underlying continuous process. The decrease in SFA proportion in the summer months is most likely to be due to a decrease in intake of long fiber combined with an increase in the PUFA content of fresh grazed swards during summer grazing in the United Kingdom. This would reduce the SFA precursors, acetate and BHBA, with de novo synthesis accounting for almost all C4:0 to C14:0 and approximately half of C16:0 
fatty acids (Grummer, 1991). Fresh pasture contains a high percentage of unsaturated fatty acids, with $\alpha$ linolenic acid (C18:3) being the predominant n-3 FA in fresh grass pastures (Dewhurst et al., 2001). Peak milk PUFA and n-3 FA proportions in the spring and early summer seen in this study coincide with changes in the grass composition occurring at these times in the United Kingdom (Dewhurst et al., 2001).

Other farm-level variables such as herd average yield and breed affected the FA proportions in milk. Increasing herd yield on conventional farms was associated with a decrease in proportion of milk n-3 FA. High-yielding cows are fed high energy density concentrate feeds, which may differ in their FA content, thus affecting milk FA composition. This, combined with a change in rumen fermentation patterns in high-yielding cows as well as a genetic difference compared with lower yielding cows, both within and between breeds, may cause variation in specific FA in milk (Peterson et al., 2002; Calus et al., 2005). In addition, the presence of mixed breed cows in the study herds increased the content of n-3 FA in milk in both organic and conventional systems. This is a potentially important area, especially in the organic sector, because one of the principles of organic farming is to utilize native breeds rather than use animals with high production intensity, such as high-yielding Holstein cows.

There was no difference in the percentage content of the major CLA isomer in bovine milk, C18:2 cis-9, trans-11, between organic and conventional milk. This contrasts with the earlier work of Jahreis et al. (1996) and Bergamo et al. (2003) who reported a higher content of CLA in organic milk. The current study included a much larger sample size of herds compared with the study by Jahreis et al. (1996), which included one organic herd studied in Germany. The study in Italy conducted by Bergamo et al. (2003) reported on the analysis of processed cows' milk samples from 2 organic sources. The current study concurs with the work by Toledo et al. (2003), which reported no difference in CLA content between organic and conventional milk. That study was conducted over 12 mo on 31 farms in Sweden; therefore, the scale of the study and farming systems in Sweden are more directly comparable with the study described in this paper. This highlights the importance of repeated studies of sufficient sample size in differing countries, to represent local management practices. However, the milk content of both CLA and vaccenic acid, which are intermediate products of biohydrogenation of FA in the ruminant, was strongly related to the month of sampling, in which the proportions sharply increased in the spring and summer months. This is most likely to be due to access to fresh pasture, which concurs with previous work showing increased milk CLA content in cows at grass (Kelly et al., 1998; Dhiman et al., 1999; Agenäs et al., 2002). Again, an effect of TMR use was seen, in which a combination of TMR use and fresh forage decreased the milk proportions of these $2 \mathrm{FA}$. Thus, comparison of organic and conventional farm management systems must take into account seasonal and nutritional factors because these may be responsible for potential differences in FA composition between organic and conventional milk. It is of interest that differences were seen in n-3 FA content, but not in the CLA content of milk, from the 2 management systems. This may suggest differences in FA biohydrogenation and metabolism occurring in cows in the 2 types of systems.

It is estimated that approximately $50 \%$ of bovine milk fat is synthesized from plasma lipids, of which $88 \%$ are from dietary origin (Grummer, 1991); therefore, changing the diet can have major effects on the milk FA content. Of the nutritional factors included in this study, 6 factors (use of TMR, grazing type, silage type, supplementary corn silage use, whole-crop use, and level of in-parlor feed) affected milk FA composition. Use of a TMR affected milk FA composition throughout the year, increasing SFA proportions, and decreasing PUFA, n-3 FA, CLA, and vaccenic acid proportions. Correct feeding using a TMR is expected to increase the long fiber intake of cows, resulting in increased SFA and decreased PUFA in milk. The effect of grazing fresh pasture or eating conserved forage affected all the FA groups. Generally, grazing of fresh grass and feeding of red-clover silage increased the milk PUFA, n-3 FA, CLA, and vaccenic acid proportions. Interestingly, grazing swards had different effects on milk SFA and n-3 FA proportions compared with the consumption of silage made from the same sward type. Thus, conserved and fresh forages may be metabolized differently by the rumen microbial population. This finding necessitates further research on the optimum grazed sward and silage type for an improved FA profile on organic and conventional farms. In this study, no independent measurements of clover type and percentage in the sward were conducted. Thus, there is a need to obtain further detail regarding sward types produced and consumed, including details of the cutting and reseeding practices to identify the optimal grassland management practices in both organic and conventional systems which will lead to milk with an improved FA profile.

The data presented here are proportions of FA contributing to the total milk FA content rather than absolute quantities, because this corrects for potential variation in the total fat content of the milk samples analyzed. Using this method of data presentation, we 
would expect a change in proportion of one FA group to be mirrored by effects on the proportions of other FA. However, this should not affect direct comparisons of specific FA proportions in different milk types at the same time points; for example, comparing organic with conventional. Also, the use of the ratio of PUFA:MUFA reduces the number of nonindependent FA comparisons in these analyses. Due to the hierarchal nature of the data, modeling of all the variables affecting milk composition is very complex and these analyses were by necessity simplified. There are some areas in which factors are not completely independent, but instead represent a complex outcome resulting from differences in breed and feed management on the farms. Thus, farm type, yield, and breed are all interconnected but the simplified structuring of the data allows summarization and interpretation.

\section{CONCLUSIONS}

Milk FA composition is affected by farming system, with organic milk consistently having a higher proportion of PUFA and n-3 FA, as well as a lower n-6:n-3 ratio. Additionally, there are several key seasonal, farm management, and cow nutrition factors that affect milk FA content. Despite accounting for management and feeding variables, an "organic" and a "conventional" effect was seen for some FA groups. This is important at the retail level, because "organic" or "conventional" labeling is one of the only differences that consumers can currently determine. There is limited identification of other herds or other processed milks with different feeding or processing strategies, some of which may not be desirable to consumers. Further studies to investigate the "organic effect" in more detail will enable the implementation of management practices that will improve milk FA composition across all systems.

\section{ACKNOWLEDGMENTS}

The financial support of the Organic Milk Suppliers Co-operative is gratefully acknowledged. The authors also acknowledge the access to farms given by all producers who participated in the study, the skilled technical services of John Tweed in the Institute of Grassland and Environmental Research at Aberystwyth and Alex Holme in the University of Liverpool. Giles Innocent was supported by the Welcome Trust funded International Partnership Research Award in Veterinary Epidemiology (IPRAVE) project.

\section{REFERENCES}

Agenäs, S., K. Holtenius, M. Griinari, and E. Burstedt. 2002. Effects of turnout to pasture and dietary fat supplementation on milk fat composition and conjugated linoleic acid in dairy cows. Acta Agric. Scand. A Anim. Sci. 52:25-33.

Baró, L., J. Fonollá, J. L. Peña, A. Martínez-Férez, A. Lucena, J. Jiménez, J. J. Boza, and E. López-Huertas. 2003. n-3 Fatty acids plus oleic acid and vitamin supplemented milk consumption reduces total and LDL cholesterol, homocysteine and levels of endothelial adhesion molecules in healthy humans. Clin. Nutr. 22:175-182.

Bergamo, P., E. Fedele, L. Iannibelli, and G. Marzillo. 2003. Fat soluble vitamin contents and fatty acid composition in organic and conventional Italian dairy products. Food Chem. 82:625631.

Bucher, H. C., P. Hengstler, C. Schindler, and G. Meier. 2002. n-3 Poly-unsaturated fatty acids in coronary heart disease: A metaanalysis of randomized controlled trials. Am. J. Med. 112:298-304.

Calus, M. P. L., M. J. Carrick, R. F. Veerkamp, and M. E. Goddard. 2005. Estimation of genetic parameters for milk fat depression in dairy cattle. J. Dairy Sci. 88:1166-1177.

Carrero, J. J., L. Baró, J. Fonollá, M. González-Santiago, A. Martınez-Férez, R. Castillo, J. Jiménez, J. J. Boza, and E. López-' Huertas. 2004. Cardiovascular effects of milk enriched with n3 polyunsaturated fatty acids, oleic acid, folic acid, and vitamins $\mathrm{E}$ and $\mathrm{B} 6$ in volunteers with mild hyperlipidemia. Nutrition 20:521-527.

Chilliard, Y., A. Ferlay, and M. Doreau. 2001. Effect of different types of forages, animal fat or marine oils in cow's diet on the milk fat secretion and composition, especially conjugated linoleic acid (CLA) and polyunsaturated fatty acids. Livest. Prod. Sci. 70:31-48.

Contreras, M. A., and S. I. Rapoport. 2002. Recent studies on interactions between $n-3$ and $n-6$ polyunsaturated fatty acids in brain and other tissues. Curr. Opin. Lipidol. 13:267-272.

Dewhurst, R. J., W. J. Fisher, J. K. S. Tweed, and R. J. Wilkins. 2003. Comparison of grass and legume silages for milk production. 1. Production responses with different levels of concentrate. J. Dairy Sci. 86:2598-2611.

Dewhurst, R. J., N. D. Scollan, S. J. Youell, J. K. S. Tweed, and M. O. Humphreys. 2001. Influence of species, cutting date and cutting interval on the fatty acid composition of grasses. Grass Forage Sci. 56:68-74.

Dhiman, T. R., G. R. Anand, L. D. Satter, and M. W. Pariza. 1999. Conjugated linoleic acid content of milk from cows fed different diets. J. Dairy Sci. 82:2146-2156.

Grummer, R. R. 1991. Effect of feed on the composition of milk fat. J. Dairy Sci. 74:3244-3257.

Hauswirth, C. B., M. R. L. Scheeder, and J. H. Beer. 2004. High n3 fatty acid content in Alpine cheese - The basis for an Alpine paradox. Circulation 109:103-107.

Hebeisen, D. F., F. Hoeflin, H. P. Reusch, E. Junker, and B. H. Lauterburg. 1993. Increased concentrations of n-3 fatty acids in milk and platelet rich plasma of grass fed cows. Int. J. Vitam. Nutr. Res. 63:229-233.

Hu, F. B., and W. C. Willett. 2002. Optimal diets for prevention of coronary heart disease. J. Am. Med. Assoc. 288:2569-2578.

Ip, C., S. F. Chin, J. A. Scimeca, and M. W. Pariza. 1991. Mammary cancer prevention by conjugated dienoic derivative of linoleic acid. Cancer Res. 51:6118-6124.

Jahreis, G., J. Fritsche, and H. Steinhart. 1996. Monthly variations of milk composition with special regard to fatty acids depending on season and farm management systems - Conventional versus ecological. Fett Lipid. 98:356-359.

Jensen, R. G. 2002. The composition of bovine milk lipids. J. Dairy Sci. 85:295-350.

Kelly, M. L., E. S. Kolver, D. E. Bauman, M. E. Van Amburgh, and L. D. Muller. 1998. Effect of intake of pasture on concentrations of conjugated linoleic acid in milk of lactating cows. J. Dairy Sci. 81:1630-1636.

Lock, A. L., and P. C. Garnsworthy. 2003. Seasonal variation in milk conjugated linoleic acid and $\Delta 9$-desaturase activity in dairy cows. Livest. Prod. Sci. 79:47-59. 
Offer, N. W., B. K. Speake, J. Dixon, and M. Marsden. 2001. Effect of fish-oil supplementation on levels of (n-3) poly-unsaturated fatty acids in the lipoprotein fractions of bovine plasma. Anim. Sci. 73:523-531.

Palmquist, D. L., A. D. Beaulieu, and D. Barbano. 1993. Feed and animal factors influencing milk fat composition. J. Dairy Sci. $76: 1753-1771$

Peterson, D. G., J. A. Kelsey, and D. E. Bauman. 2002. Analysis of variation in cis-9, trans-11 conjugated linoleic acid (CLA) in milk fat of dairy cows. J. Dairy Sci. 85:2164-2172.

Rose, D., and J. M. Connolly. 1999. Omega-3 fatty acids as cancer chemopreventive agents. Pharmacol. Ther. 83:217-244.

Saadatian-Elahi, M., T. Norat, J. Goudable, and E. Riboli. 2004. Biomarkers of dietary fatty acid intake and the risk of breast cancer: A meta-analysis. Int. J. Cancer 111:584-591.

Simopoulos, A. P. 2002. The importance of the ratio of omega-6/ omega-3 essential fatty acids. Biomed. Pharm. 56:365-379.

Sukhija, P. S., and D. L. Palmquist. 1988. Rapid method for determination of total fatty acid content and composition of feedstuffs and feces. J. Agric. Food Chem. 36:1202-1206.

Thorsdottir, I., J. Hill, and A. Ramel. 2004a. Seasonal variation in cis-9, trans-11 conjugated linoleic acid content in milk fat from Nordic countries. J. Dairy Sci. 87:2800-2802.
Thorsdottir, I., J. Hill, and A. Ramel. 2004b. Omega-3 fatty acid supply from milk associated with lower type 2 diabetes in men and coronary heart disease in women. Prev. Med. 39:630-634.

Toledo, P., A. Andrén, and L. Björck. 2002. Composition of raw milk from sustainabale production systems. Int. Dairy J. 12:75-80.

Visioli, F., P. Risè, E. Plasmati, F. Pazzucconi, C. R. Sirtori, and C. Galli. 2000. Very low intakes of n-3 fatty acids incorporated into bovine milk reduce plasma triacylglycerol and increase HDLcholesterol concentrations in healthy subjects. Pharmacol. Ther. 41:571-576.

Voigt, J., and H. Hagemeister. 2001. Dietary influence on a desirable fatty acid composition in milk from dairy cattle. J. Anim. Feed Sci. 10:87-103.

Whigham, L. D., M. E. Cook, and R. L. Atkinson. 2000. Conjugated linoleic acid: Implications for human health. Pharm. Res. 42:503-510.

White, S. L., J. A. Bertrand, M. R. Wade, S. P. Washburn, J. T Green, and T. C. Jenkins. 2001. Comparison of fatty acid content of milk from Jersey and Holstein cows consuming pasture or a total mixed ration. J. Dairy Sci. 84:2295-2301.

Wijesundera, C., Z. Shen, W. J. Wales, and D. E. Dalley. 2003. Effects of cereal grain and fibre supplements on the fatty acid composition of milk fat of grazing dairy cows in early lactation. J. Dairy Res. 70:257-265. 